\title{
QUEEN'S
UNIVERSITY
BELFAST
}

\section{Microclimate has a greater influence than macroclimate on the availability of infective Haemonchus contortus larvae on herbage in a warmed temperate environment}

Wang, T., Vineer, H. R., Morrison, A., van Wyk, J. A., Bolajoko, M-B., Bartley, D. J., \& Morgan, E. R. (2018). Microclimate has a greater influence than macroclimate on the availability of infective Haemonchus contortus larvae on herbage in a warmed temperate environment. Agriculture, Ecosystems and Environment, 265, 31-36. https://doi.org/10.1016/j.agee.2018.05.029

Published in:

Agriculture, Ecosystems and Environment

Document Version:

Peer reviewed version

Queen's University Belfast - Research Portal:

Link to publication record in Queen's University Belfast Research Portal

\section{Publisher rights}

This manuscript is distributed under a Creative Commons Attribution-NonCommercial-NoDerivs License

(https://creativecommons.org/licenses/by-nc-nd/4.0/), which permits distribution and reproduction for non-commercial purposes, provided the author and source are cited.

\section{General rights}

Copyright for the publications made accessible via the Queen's University Belfast Research Portal is retained by the author(s) and / or other copyright owners and it is a condition of accessing these publications that users recognise and abide by the legal requirements associated with these rights.

Take down policy

The Research Portal is Queen's institutional repository that provides access to Queen's research output. Every effort has been made to ensure that content in the Research Portal does not infringe any person's rights, or applicable UK laws. If you discover content in the Research Portal that you believe breaches copyright or violates any law, please contact openaccess@qub.ac.uk. 
1 Microclimate has a greater influence than macroclimate on the

2 availability of infective Haemonchus contortus larvae on herbage in a

3 warmed temperate environment

4

5 Tong Wang ${ }^{1,2}$, Hannah Rose Vineer ${ }^{1}$, Alison Morrison ${ }^{3}$, Jan A. van Wyk ${ }^{4}$,

6 Muhammad-Bashir Bolajoko ${ }^{1}$, David J. Bartley ${ }^{3}$, Eric R. Morgan ${ }^{1,5^{*}}$

$7{ }^{1}$ University of Bristol, School of Biological Sciences, Bristol Life Sciences Building,

824 Tyndall Avenue, Bristol BS8 1TQ, United Kingdom.

$9{ }^{2}$ Faculty of Veterinary Medicine, University of Calgary, 2500 University Drive NW, 10 Calgary, AB, T2N 1N4, Canada.

$11{ }^{3}$ Moredun Research Institute, Pentlands Science Park, Bush Loan, Penicuik EH26 0PZ, 12 United Kingdom.

$13{ }^{4}$ Department of Veterinary Tropical Diseases, Faculty of Veterinary Science, University 14 of Pretoria, Private Bag X04, Onderstepoort 0110, South Africa.

$15{ }^{5}$ School of Biological Sciences, Queen's University Belfast, 97 Lisburn Road, Belfast, 16 BT9 7BL, United Kingdom.

$17 *$ Corresponding author: eric.morgan@bristol.ac.uk 


\section{Abstract}

Global climate change is altering epidemiological patterns of gastrointestinal nematode infections in grazing livestock, including through effects of temperature and moisture on the availability of infective third-stage larvae (L3). While considerable experimental effort has been devoted to the influences of climate on L3 development and survival in major nematode species, knowledge of effects on L3 migration out of faeces and onto herbage is more limited. In this study, we examined elements of this process for Haemonchus contortus in controlled and natural climates. The effect of temperature on migration rate from faeces was quantified and found to peak at $15^{\circ} \mathrm{C}$. In glasshouses, a $3{ }^{\circ} \mathrm{C}$ difference in mean temperature failed to produce a statistically significant difference in the number of $\mathrm{L} 3$ reaching herbage after a single rainfall event, and faecal moisture content (FMC) did not decline significantly more rapidly at the higher temperatures. Most larvae left the faeces and reached the grass within 3 hours after simulated rainfall. On natural pasture in temperate summer, FMC was strongly affected by microclimate, with shade and long grass both significantly slowing drying. Results suggest that microclimate is important in determining FMC and larval migration, and that its effects can be greater than those of macroclimate, e.g. moderate differences in average ambient temperature. More work is needed to develop a full predictive understanding of larval availability in natural settings, which is the product of interacting factors acting on overlapping parasite cohorts.

Key words: nematode, parasite, climate change, transmission, epidemiology, faecal moisture content, temperature, rainfall, migration 


\section{Introduction}

The abomasal nematode parasite Haemonchus contortus causes major problems to the health and productivity of sheep and goats, especially in tropical and sub-tropical areas with adequate rainfall (Waller, 1997; Perry and Randolph, 1999; O'Connor et al., 2006; van Dijk et al., 2010; Besier et al., 2016). Improved conditions for transmission are further predicted in temperate areas under climate change scenarios (Rose et al., 2016), where resistance to anthelmintic drugs threatens to undermine control (Rose et al. 2015a). Temperature and moisture have long been known to be important for the development, survival and translation of infective third stage H. contortus larvae (L3) onto herbage (Veglia, 1915; Rossanigo and Gruner, 1995; O’Connor et al., 2007; 2008). Previous experiments have attempted to characterize the effects of individual climatic factors on components of the $H$. contortus life cycle under controlled conditions (e.g. Hsu \& Levine, 1977; Coyne \& Smith, 1992), and relationships between climate and infection pressure have been widely observed in the field (e.g. Rose 1963; Onyali et al., 1990; Troell et al., 2005; Silva et al., 2008).

How temperature and rainfall interact to influence L3 migration out of faeces has received less attention (Todd et al., 1976; Hsu \& Levine, 1977, Pandey et al., 1989; Van Dijk and Morgan, 2011; Wang et al., 2014). Under climate change scenarios, variability in temperature and rainfall is predicted to increase (Mason et al., 1999; Pinault, 2012), so the effect of short-term climatic conditions on larval availability, e.g. following brief rainfall events, and the modifying influence of pasture microclimate, might significantly alter transmission patterns. Increased temperatures could hypothetically 
accelerate larval movement out of faeces, while simultaneously leading to faster drying of faeces and thus a shorter period of migration. The net effect of warmer temperatures on migration is therefore hard to predict.

This study aims to determine how temperature and rainfall interact to influence migration of infective $H$. contortus larvae from faeces onto grass, and how this is modified by variation in microclimate. Hence, to assess the likely net impact of realistic gradual climate warming on L3 availability in temperate environments. The overall objective is to improve ability to predict infection patterns under climate change, in order to inform farm adaptation strategies (Morgan and Wall 2009), as part of wider attempts to understand ecological responses of parasites to global change (Cable et al. 2017).

\section{Materials and methods}

\subsection{General methods}

\subsubsection{Mono-infected faecal samples}

Faecal samples from mono-cultures of MHco3(ISE) isolate $H$. contortus in sheep (Rose Vineer et al., 2017) were provided by the Moredun Research Institute (Edinburgh, U.K.). Briefly, lambs were born and reared indoors to ensure that they were free of preexisting nematode infections. Donor lambs were drenched orally by syringe with 5,000 L3 in a suspension of tap water. Faecal egg counts (FEC) were checked 21 days later, and individual sheep with sufficient egg output were harnessed and a bag attached to collect faeces over a 24-hour period. Faecal samples were placed in a sealed plastic bag 
and sent by post to the laboratory in Bristol, to arrive within 24 hours. A modified McMaster method (MAFF, 1986) was used to verify estimated egg density on arrival and ensure that development of eggs was not discernible before starting the experiments.

\subsubsection{Larval culture and recovery}

For Experiments 1 and 2 below, L3 were prepared as follows. Faeces containing $H$. contortus eggs were placed in six-well plates (Sterilin, U.K.) with a loose lid and incubated at $20{ }^{\circ} \mathrm{C}$ for seven days (Versatile Environmental Test Chamber, Sanyo, Japan). Lids were removed briefly each day to ensure enough air exchange for development, without the danger of excessive drying. Faeces containing fully developed L3 were used for the experiments, which aimed to test larval emergence from faeces. Following the various treatments, L3 were harvested from cultured faeces using a modified Baermann technique (Gruner, 1986), and species identity confirmed using the identification keys described in Van Wyk \& Mayhew (2013).

\subsubsection{Larval extraction from herbage}

The method used in Experiment 2 to recover L3 from herbage was derived from several different studies (Martin et al., 1990; Couvillion, 1993; Van Bezooijen, 2006). Grass was cut using scissors at the base of the plant, as close to the soil as possible without including soil or roots, and immediately wrapped in a square of woven cotton muslin cloth, forming a loose ball, and the muslin secured with a clip. A $250 \mathrm{ml}$ inverse conical flask was filled with water until it reached about $1 \mathrm{~cm}$ below the rim, a few drops 
of detergent were added, and herbage samples were submerged in the water. After standing for 12 hours, samples were removed and set aside, and the water decanted, leaving about $10 \mathrm{ml}$ of water containing the sediment, including larvae and debris. This residue was agitated and poured into a soft-walled flexible plastic test tube and centrifuged for 2 minutes at 1500rpm (c. 400g). Supernatant was then carefully removed by siphoning from the top of the tube, leaving $1 \mathrm{ml}$ of sediment. Sucrose solution of specific gravity 1.17 was added to fill two thirds of the tube, which was then centrifuged again at $400 \mathrm{~g}$ to float the larvae. In order to capture all the larvae, the test tube was clamped with haemostatic forceps about $5 \mathrm{~mm}$ below the surface, and inverted to pour the larval suspension into a beaker. The top portion of the clamped tube was then rinsed with water to recover any remaining larvae, and the rinsing water combined with the larval suspension. The whole suspension was then transferred to a standard test tube, topped up to $10 \mathrm{ml}$ with water, and inverted several times to mix the larval suspension. A $1 \mathrm{ml}$ aliquot of the suspension was transferred into a Sedgewick Rafter nematode counting chamber together with one drop of Lugol's iodine, and the larvae counted under $\times 40$ total magnification. The number of larvae obtained was multiplied by 10 to estimate total number present in the herbage sample.

The efficiency of the above method was evaluated as follows. Herbage from ungrazed pasture was harvested as above, and 10 equal $5 \mathrm{~g}$ aliquots cut into $1 \mathrm{~cm}$ pieces and each wetted with $1 \mathrm{ml}$ larval suspension that contained $399 \pm 25$ (mean \pm standard deviation) H. contortus L3, evenly distributed by pipette throughout the herbage. After settling for 30 minutes, larvae were recovered from herbage using the above method 
and counted to estimate the recovery rate.

\subsubsection{Rainfall simulation}

A portable rainfall simulator was applied in Experiment 2 below to standardize rainfall delivery. This consisted of a pressurized nozzle with a rubber hose connected to a tap, from which water was released at uniform intensity. For the purpose of calibration, the simulator was run for 1 minute, $1 \mathrm{~m}$ above an array of cylindrical beakers, and the vertical height and volume of water recovered from each beaker was recorded. The average value showed that rainfall was delivered at a rate of $1.4 \mathrm{~mm} / \mathrm{min}$, and this was applied to estimates of rainfall requirements for larval migration.

\subsection{Experimental design}

This study aimed to quantify the rate of L3 migration from faeces at a range of constant temperatures without moisture limitation (experiment 1). Secondly, to quantify L3 migration following temporary rewetting of faeces in controlled environments (experiment 2) and, finally, the rate of drying of faeces on natural pasture (experiment $3)$.

\subsubsection{Experiment 1: Effect of temperature on the migration of $H$. contortus $L 3$ from}

\section{faeces}

Migration of L3 was assessed using a mesh sieve apparatus based on that in Wang et al. (2014). Five faecal pellets containing $H$. contortus $\mathrm{L} 3$ were placed on a sieve 10 
$\mathrm{cm}$ in diameter and of aperture $0.9 \mathrm{~mm}$, which was inserted into a plastic cup. In order to create ideal moisture for migration, a fine water mist was applied to the pellets using a pressurized garden sprayer (Spraymist 1.251, Hozelock, UK) for $20 \mathrm{~s}$ from a distance of around $1 \mathrm{~m}$. The experimental units were then transferred immediately to, and maintained in, covered plastic boxes at relative humidity $(\mathrm{RH})$ of $95 \%$, which were kept stored at $7,10,15,20,25$ and $33{ }^{\circ} \mathrm{C}$ for one hour, with four units in each box. Faecal pellets were then transferred to a series of new sieves, each of which was inserted into a new plastic cup, and the same spraying treatment was once more applied to keep the faeces moist, before again placing them into the constant temperature boxes. Larvae that had migrated from the faeces onto the first sieve during incubation were washed into the respective cups and allowed to sediment for $12 \mathrm{~h}$, after which the supernatant was siphoned off with a pipette. The bottom $10 \mathrm{ml}$ of water containing larvae was mixed and a $1 \mathrm{ml}$ aliquot was transferred into a nematode counting chamber. The process of larval recovery was repeated eight times at intervals of one hour. At the end of the experiment, the number of larvae remaining in the pellets was estimated by Baermann extraction, enabling calculation of the proportion of total recoverable L3 present that had migrated out of the faeces at each time point, and at each temperature. Owing to the ideal moisture conditions and short experimental time, mortality of L3 was ignored. For each temperature treatment, the mean cumulative proportion of L3 that had left the faeces was calculated for each time point (h) and then logistically transformed as follows:

$$
y=\log _{10}\left(\frac{x}{1-x}\right)
$$


172

173

where $x$ is the proportion of L3. Linear regression of $y$ against time (h) was applied to identify the intercept on the horizontal axis, which identifies the number of hours needed for $50 \%$ of L3 to migrate out of faeces (M50) (Azam et al., 2012).

The hourly migration rate, $\gamma$, for each temperature was then calculated as follows:

$$
\gamma=-\ln (0.5) / M 50
$$

Regression analysis was then used to estimate the relationship between migration rate and temperature.

\subsubsection{Experiment 2: Migration of larvae onto grass in baseline and warmed temperate}

\section{conditions}

The experiment was conducted in two glasshouses, one of which was cooled by air conditioning by around $3^{\circ} \mathrm{C}$ (baseline $=$ cool) relative to the unregulated glasshouse (warmed). Use of glasshouses allowed for comparison of larval dynamics between treatments similar in the range and pattern of temperature fluctuation, but consistently different in mean temperature level. Mean temperatures in the glasshouses during the experiment were $19.4 \pm 1.0^{\circ} \mathrm{C}$ (mean \pm standard deviation; range 17.8-22.5) and $22.5 \pm$ $2.3^{\circ} \mathrm{C}$ (range 19.1-28.7). The temperature difference between glasshouses was constrained by the ability of the air conditioning unit to cool the large uninsulated air space under solar irradiation, and in any case approximate to those observed in temperate summers, and match medium term climate change projections (Rose et al. 2015a). Relative air humidity averaged $76 \%$ in the cool and $62 \%$ in the warm greenhouse. Grass turf squares measuring $20 \times 20 \mathrm{~cm}$ were used to evaluate larval 
migration onto herbage in the hours after a single rainfall event: these dimensions were chosen because Skinner \& Todd (1980) showed that over 90\% of larvae on grass were found within $10 \mathrm{~cm}$ of the faeces from which they originated. Turf was approximately $2 \mathrm{~cm}$ thick and composed of natural grass turf purchased from a garden centre, with no prior exposure to livestock faeces. Experiments were conducted in daylight, beginning around 9am.

A pilot study was first conducted to determine the approximate duration of the window of opportunity for L3 migration following a single rainfall event. Five moist faecal pellets containing L3 (average 2824 per square, standard deviation 659) were placed on each turf square and four replicates were included in each glasshouse. A single simulated rainfall event of approximately $2 \mathrm{~mm}$ was applied with the calibrated rainfall simulator immediately after faecal deposition, based on the threshold amount needed for larval migration from hydrated pellets in Wang et al. (2014). Six and 24 hours after rain, faecal pellets were carefully transferred to a new turf square with forceps and the old square was collected in a sealed plastic bag and brought to the laboratory. Herbage was processed using the technique described in 2.1.3 above to recover migrated L3 from the grass. L3 remaining in the faeces were recovered by the modified Baermann technique at the end of the experiment. Recovery of larvae sequestered in the soil-root layer was also attempted by the Baermann method, but none were recovered and this compartment was ignored in the main experiment.

The main experiment followed the same method of the pilot and used the same faecal material but included two extensions. Firstly, additional turf squares with faecal 
pellets were placed in equal numbers beside the experimental replicates to determine FMC at intervals by weighing the pellets and drying in an oven at $90{ }^{\circ} \mathrm{C}$ for 12 hours before re-weighing. Secondly, L3 recovery was undertaken every three hours, for the first nine hours after rainfall. L3 remaining in the faeces were again recovered by the modified Baermann technique after 24 hours.

The number of $\mathrm{L} 3$ recovered at each time point $\left(\mathrm{N}_{i}\right)$ was expressed as the proportion of the total number of L3 estimated to be present by adding those recovered at all time points from the grass and from the faeces at the end of the experiment. The arithmetic mean proportion of L3 recovered was plotted against time for each glasshouse, and subjected to arcsine transformation prior to formal analysis. A general linear model (GLM) was used to test the effect of variables on the proportion of L3 present on the herbage, with Tukey's post hoc test applied to significant outcomes. The variables included were glasshouse condition (cool or warm) and collection time ( $3 \mathrm{~h}$ and $6 \mathrm{~h}$ ). Recovery at $9 \mathrm{~h}$ was not analyzed because no additional L3 were recovered from herbage $9 \mathrm{~h}$ after rain. The effect of glasshouse condition (cool or warm) on FMC after rainfall was analyzed using the Mann-Whitney $\mathrm{U}$ test. Temperature data and $\mathrm{L} 3$ results were then applied together to determine the duration of the 'migration window'. Thus, the known number of starting L3 in each replicate, the proportion of L3 observed to leave faeces, and the rate of migration derived from the regression on temperature derived in section 2.2.1 above, were used to estimate the duration for which migration was possible. Observed and predicted numbers of L3 during that period were compared using Pearson's correlation. Model efficiency (EF; Mayer \& Butler, 1993) was applied 
to evaluate the model (Equation 3):

$$
E F=1-\frac{\sum\left(y_{i}-\hat{y}_{i}\right)^{2}}{\sum\left(y_{i}-\bar{y}\right)^{2}}
$$

where $y_{i}=$ observed number of migrated L 3 and $\hat{y}=$ predicted number of migrated L3.

\subsubsection{Experiment 3: Faecal moisture loss in the field}

A field study was carried out to investigate the rate of moisture loss from faeces on pasture under natural conditions, on un-grazed pasture in a sheep farming area in southwest France. The pasture was mown every few weeks, but unevenly such that it included different heights of grass. During the experiment, the air temperature taken at surface level varied from $21^{\circ} \mathrm{C}$ to $37^{\circ} \mathrm{C}$, with wide diurnal fluctuations. Faecal samples were collected from grazing lambs on a nearby farm. Faecal moisture loss was measured under four different conditions, with four replicates for each group: short grass $(<1 \mathrm{~cm})$ with and without shade and long grass $(10-25 \mathrm{~cm})$ with and without shade. Shade was produced by fixing a square of cardboard $15 \mathrm{~cm}$ above the ground, allowing for circulation of air beneath the canopy. Faeces were placed on plastic mesh (1 mm grid size) to facilitate transfer for weighing and to reduce loss from dung-burying beetles. All replicates were placed in position at 12:30 pm on day 1 and weighed five times, at $1 \mathrm{pm}, 5 \mathrm{pm}$, and $8 \mathrm{pm}$ on day 1 and 10:30 am and $5 \mathrm{pm}$ on day 2. FMC was plotted against time for each treatment, then arcsine transformed to stabilise the variance and analysed in a GLM with grass length and shade included as factors.

\section{Results}


3.1 Experiment 1: Effect of temperature on the migration of $H$. contortus $L 3$ from faeces Migration rate was lowest at low and high temperatures, so a polynomial regression model was fitted, which predicted maximum migration rate at $15^{\circ} \mathrm{C}$ (Fig. 1).

\subsection{Experiment 2: Migration of larvae onto grass in baseline and warmed conditions}

The proportion of $H$. contortus L3 recovered from grass using the modified Baermann technique was $0.68 \pm 0.14$ (mean of 10 replicates \pm standard deviation).

Results of the pilot study showed that almost all migration onto grass occurred between $0 \mathrm{~h}$ and $6 \mathrm{~h}$ after wetting by simulated rainfall (Fig. 2), with no significant difference between cool and warm glasshouses.

In the main experiment, FMC on the day of deposition was $64 \%$ in both glasshouses and increased to $69 \%$ (cool house) and 68\% (warm house) after rainfall, then decreased gradually. Change in FMC in warm and cool glasshouses did not differ significantly over the course of the experiment (Mann-Whitney $\mathrm{U}_{46}=284.5, \mathrm{p}=0.947$ ) (Fig. 3).

There was no significant difference in L3 migration between warm and cool glasshouses $\left(F_{1,18}=0.8, \mathrm{p}=0.783\right)$, but the proportion of $\mathrm{L} 3$ recovered differed with time of collection $\left(F_{2,18}=24.8, \mathrm{p}<0.001\right)$. Post hoc Tukey's HSD tests showed that significantly more L3 were recovered from herbage in the first collection, i.e. more larvae migrated onto the grass $0-3 \mathrm{~h}$ (mean proportion $=0.57 \pm$ standard deviation 0.26 ) than 3-6 h $(0.05 \pm 0.05)$ after rain $(\mathrm{p}<0.001)$ (Fig. 4). No further L3 were recovered 9 $\mathrm{h}$ after rain. On average, a proportion of $0.38 \pm 0.21$ of $\mathrm{L} 3$ remained in the faeces at the end of the 24-hour experiment. 

that predicted from temperature (section 3.1) and the duration of permissive FMC (Pearson $\mathrm{r}=0.912, \mathrm{p}=0.002$ ), notwithstanding some over- and under-prediction (Fig. available data. rain shower between 28 and $44 \mathrm{~h}$ post deposition. Faecal weight decreased most significantly in the 'short sun' group, with the lowest FMC recorded as $37 \%$, after 52 samples being removed or destroyed in this way and thus excluded from the analysis. preliminary comparisons of the relative influences of macroclimate and microclimate on larval migration. While there have been some previous studies on the effect of 
temperature on the vertical migration of gastrointestinal nematode larvae onto herbage (e.g. Silangwa \& Todd, 1964; Callinan \& Westcott, 1986), none have specifically reported on the impact of temperature on horizontal migration out of faeces. In the absence of moisture limitation, our results showed a convex curve, with the fastest migration occurring at intermediate temperatures around $15^{\circ} \mathrm{C}$. There was very little difference in average migration rate between 7 and $20^{\circ} \mathrm{C}$, and rates decreased at 25-30 ${ }^{\circ} \mathrm{C}$. This was unexpected given the general tendency of metabolism to accelerate with increasing temperature, and could be an adaptation to conserve limited energy resources (Fenton and Rands, 2004) or to avoid exposure to adverse conditions for survival such as lethal ultraviolet radiation high on herbage in sunny conditions (Van Dijk et al., 2009), by remaining in protected micro-environments. Although the experimental conditions and methods were different, Buckley (1940) and Callinan and Westcott (1986) also regarded $15^{\circ} \mathrm{C}$ to be the optimal temperature for the migration of trichostrongylid L3, while Rees (1950) and Callinan and Westcott (1986) further found that extremes of very high and very low temperatures inhibited directional larval movement. Even at temperatures of $25-30{ }^{\circ} \mathrm{C}$ in the present study, however, more than $10 \%$ of L3 were able to leave the faeces per hour. It is clear from the present and previous results (Wang et al., 2014) that, at least in temperate conditions, temperature is a less important factor than availability of moisture for the migration process, which occurs rapidly when conditions permit.

In the glasshouses, temperature fluctuated with outdoor temperature, but remained in a range favourable for larval migration. The average overall temperature difference 
between the two glasshouses was $3.1{ }^{\circ} \mathrm{C}$, which equates to moderate global climate warming scenarios for temperate areas (Rose et al. 2016). Our working hypothesis before the experiment was that hydrated faeces dry faster at high temperatures and the window of opportunity for migration following wetting by a rainfall event will therefore be shorter than at low temperatures. In fact, faecal drying rate was similar in both greenhouses, with only $9 \%$ FMC loss in the first 9 hours, and ambient temperature consequently made little difference to L3 migration rate. In field conditions, different microclimatic conditions showed strong effects on faecal drying rates. Faeces deposited in sunshine on short grass dried much more quickly than those placed in long grass under shade, and within 24 hours FMC was below $60 \%$ and therefore too dry to permit L3 migration following light rainfall (Wang et al. 2014). Under artificial shade or that provided by long grass, FMC remained well above $60 \%$ for at least twice as long, prolonging the window during which larval migration would occur following a light rain shower.

By quantifying L3 migration rates under different conditions, the present study provides additional information to support mechanistic prediction of climatic impacts on infection patterns. Thus, most migration onto grass occurred within $3 \mathrm{~h}$ after rain, with migration declining thereafter. An average of $38 \%$ of L3 remained in faecal pellets 6-24 $\mathrm{h}$ after rain, indicating the closure of the migration window within $6 \mathrm{~h}$, presumably as a result of disappearance of the surface water film (Van Dijk et al. 2011; Wang et al. 2014). Under continuous moisture, L3 migration is generally complete within 24 hours (Silangwa and Todd, 1964; Callinan and Westcott, 1986). Further studies will be needed 
to more thoroughly characterize L3 migration across a wider range of temperature, rainfall and other environmental conditions such as wind (Krecek et al., 1992) and irradiation (Van Dijk et al. 2009), in order to refine existing predictive models (e.g. Rose et al. 2015b; Walker et al. 2018). The present results show that factors influencing microclimate on pasture should be taken into account in such studies, and could be especially important in environments more extreme than considered here. The interface between faeces, soil and herbage on natural pasture also mediates larval migration onto grass, with complex L3 movement between these compartments (Rose et al., 2015b), while soil moisture is already known to strongly influence L3 development in faeces (Khadijah et al. 2013a,b) and possibly translation onto pasture (Khadijah et al. 2013c). Dung burial, e.g. by invertebrates, has been shown to affect L3 availability (Fincher, 1973; Gronvold, 1979; Waghorn et al. 2002; Sands and Wall 2018), with net effects probably depending on climate, soil type and biodiversity. Although larval recovery from soil was unsuccessful in the experiments reported on here, possibly due to the dense turf structure and shallow soil/root layer with little free soil present, sequestration in soil could be an important modifier of larval availability under natural field conditions. Previous results vary widely, sometimes finding many larvae in soil (Callinan \& Westcott, 1986; Krecek, et al., 1995; Leathwick, et al., 2011) and sometimes not (Crofton, 1948; Rose \& Small, 1985).

The experiments reported here used a laboratory-maintained strain of $H$. contortus whose origin is obscure and likely tropical, and this might have affected its response to climate (Besier et al. 2016). The temperature-development profile of this isolate was 
found to be similar to field isolates from Europe (Rose Vineer et al. 2016). Nevertheless, use of field populations for future experiments on climatic drivers of transmission would be preferable, to take account of natural variation and potential adaptation to local environments. Work on related nematode species has further shown wide withinpopulation variability in response to climate, which might constitute adaptation to unpredictable environmental conditions (Van Dijk and Morgan 2010).

This study shows the potential importance of microclimate, in contrast to macroclimate, in determining rate of faecal drying and hence the effects of subsequent rainfall on L3 release. In the field, pasture will contain faecal pellets at a wide range of times since deposition, and in a range of microclimates, as well as larvae in soil, dung beetles and the herbage mat; the effect of rainfall on larval migration onto herbage is therefore likely to be complex. More sophisticated models and supporting experiments will therefore be needed to adequately predict the effects of climate change on larval availability.

\section{Acknowledgements}

This study was funded by the UK Biotechnology and Biological Sciences Research Council (BBSRC) under CIDLID project (BB/H00940X/1 RISCNET) and EU FP7 STREP project GLOWORM (FP7-KBBE-2011-5-288975). EM is supported by BBSRC projects BB/M003949/1 and BB/R010250/1. We are grateful to Hannah Johnston and Sharon Shin for assistance with the laboratory and glasshouse experiments, and to the community of La Grand' Mothe, Brigueil-le-Chantre, 86290 
392

393

394

395

396

397

398

399

400

401

402

403

404

405

406

407

408

409

410

411

412

France, for kind permission to use communal land for the field experiment. We appreciate the constructive comments of three anonymous reviewers.

\section{References}

Andersen, F.L., Levine, N.D., 1968. Effect of desiccation on survival of the free-living stages of Trichostrongylus colubriformis. J. Parasitol. 54, 117-128.

Azam, D., Onyinye, M.U., Ashraf, S., Gamal, A. Abd-Allah., Morgan, E.R., 2012. Temperature and the development and survival of infective Toxocara canis larvae. Parasitol. Res. 110, 649-656.

Besier, R.B., Kahn, L.P., Sargison, N.D., Van Wyk, J.A., 2016. The pathophysiology, ecology and epidemiology of Haemonchus contortus infection in small ruminants. Adv. Parasitol. 93, 95-143.

Bryan, R.P., Kerr, J.D., 1989. Factors affecting the survival and migration of the freeliving stages of gastrointestinal nematode parasites of cattle in central Queensland. Vet. Parasitol. 30, 315-326.

Byrd, D.W., Barker, K.R., Ferris, H., Nusbaum, C.J., Griffin, W.E., Small, R.H., Stone, C.A., 1976. Two semi-automatic elutriators for extracting nematodes and certain fungi from soil. J. Nematol. 8, 206-212.

Buckley, J., 1940. Observations on the vertical migrations of infective larvae of certain bursate nematodes. J. Helminthol. 18, 173-182.

Callinan, A. \& Westcott, J.M., 1986. Vertical distribution of trichostrongylid larvae on herbage and in soil. Int. J. Parasitol. 16, 241-244. 
414

415

416

417

418

419

420

421

422

423

424

425

426

427

428

429

430

431

432

433

Cable, J., Barber, I., Boag, B., Ellison, A., Morgan, E.R., Murray, K., Pascoe, E.L., Sait, S.M., Wilson, A.J. \& Booth, M., 2017. Global change, parasite transmission and disease control: lessons from ecology. Phil. Trans. R. Soc. B Biol. Sci. 372, 1719, 20160088.

Couvillion, C.E., 1993. Estimation of the numbers of trichostrongylid larvae on pasture. Vet. Parasitol. 46, 197-203.

Coyne, M.J. \& Smith, G., 1992. The development and mortality of the free-living stages of Haemonchus contortus in laboratory culture. Int. J. Parasitol. 22, 641-650.

Fenton, A and Rands, S.A, 2004. Optimal parasite infection strategies: a statedependent approach. Int. J. Parasitol. 34, 813-821.

Crofton , H. D., 1948. The ecology of immature phases of trichostrongyle neamtodes. (1) The vertical distribution of infective larvae of Trichostrongylus retortaeformis in relation to their habitats. Parasitology $39,17-25$.

Fincher, G.T., 1973. Dung beetles as biological control agents for gastrointestinal parasites of livestock. J. Parasitol. 59, 396-399.

Grønvold, J., 1979. On the possible role of earthworms in the transmission of Ostertagia ostertagi third-stage larvae from feces to soil. J. Paratitol. 65, 831-832.

Gruner, L., 1986. Strongyle larval recovery from ovine faeces sampled on pasture: efficiency of the Baermannization and epidemiological interest of the technique. In: IVth International Symposium of Veterinary Laboratory Diagnosticians Abstracts June 2-6. Amsterdam: The Netherlands, pp. 186-189. 
Hsu, C.K. \& Levine, N.D., 1977. Degree-day concept in development of infective larvae of Haemonchus contortus and Trichostrongylus colubriformis under constant and cyclic conditions. Am. J. Vet. Res. 38, 1115-1119.

Khadijah, S., Kahn, L.P., Walkden-Brown, S.W., Bailey, J.N., Bowers, S.F., $2013 a$. Effect of simulated rainfall timing on faecal moisture and development of Haemonchus contortus and Trichostrongylus colubriformis eggs to infective larvae. Vet. Parasitol. 192, 199-210.

Khadijah, S., Kahn, L.P., Walkden-Brown, S.W., Bailey, J.N., Bowers, S.F., 2013b.

Soil moisture modulates the effects of the timing and amount of rainfall on faecal moisture and development of Haemonchus contortus and Trichostrongylus colubriformis to infective third stage larvae. Vet. Parasitol. 196, 347-357.

Khadijah, S., Kahn, L.P., Walkden-Brown, S.W., Bailey, J.N., Bowers, S.F., 2013c. Translation of $H$. contortus and T. colubriformis from egg to establishment in grazing sheep is unaffected by rainfall timing, rainfall amount and herbage height under conditions of high soil moisture in the Northern Tablelands of NSW. Vet. Parasitol. 197, 204-211.

Krecek, R.C., Groeneveld, H.T. \& Maritz, J.I., 1992. A preliminary study of the effect of microclimate on third-stage larvae of Haemonchus contortus and Haemonchus placei on irrigated pasture. Int. J. Parasitol. 22, 747-752.

Krecek, R. C., Hartman, R., Groeneveld, H. T. \& Thorne, A., 1995. Microclimatic effect on vertical migration of Haemonchus contortus and Haemonchus placei third-stage larvae on irrigated Kikuyu pasture. Onderstepoort J. Vet. Res. 62, 117-122. 
Leathwick, D. M., Miller, C. M. \& Waghorn, T. S., 2011. Development and spatial distribution of the free-living stages of Teladorsagia circumcincta and Trichostrongylus colubriformis on pasture: A pilot study. New Zealand Vet. J. 59, 272-278.

MAFF, 1986. Fisheries and Food, Reference Book. In: Manual of Veterinary Parasitological Laboratory Techniques. London: Ministry of Agriculture, HMSO. pp. 5. Martin, R.R., Beveridge, I., Pullman, A.L. \& Brown, T.H., 1990. A modified technique for the estimation of the number of infective nematode larvae present on pasture, and its application in the field under South Australian conditions. Vet. Parasitol. 37, 133143.

Mason, S.J. et al., 1999. Changes in extreme rainfall events in South Africa. Climate Change 41, 249-257.

Mayer, D.G. \& Butler, D.G., 1993. Statistical validation. Ecol. Model. 68, 21-32.

Morgan, E.R. \& Wall, R., 2009 Climate change and parasitic disease: farmer mitigation? Trends Parasitol. 25, 308-313

Morgan, E.R. \& Van Dijk, J., 2012. Climate and the epidemiology of gastrointestinal nematode infections of sheep in Europe. Vet. Parasitol. 189, 8-14.

O'Connor, L.J., Walkden-Brown, S.W. \& Kahn, L.P., 2006. Ecology of the free-living stages of major trichostrongylid parasites of sheep. Vet. Parasitol. 142, 1-15.

O' Connor, L.J., Kahn, L.P. \& Walkden-Brown, S.W., 2007. Moisture requirements for the free-living development of Haemonchus contortus: Quantitative and temporal effects under conditions of low evaporation. Vet. Parasitol. 150, 128-138.

O' Connor, L.J., Kahn, L.P. \& Walkden-Brown, S.W., 2008. Interaction between the 
478

479

480

481

482

483

484

485

486

487

488

489

490

491

492

493

494

495

496

497

498

499

effects of evaporation rate and amount of simulated rainfall on development of the freeliving stages of Haemonchus contortus. Vet. Parasitol. 155, 223-234

Onyali, I.O., Onwuliri, C. \& Ajayi, J.A., 1990. Development and survival of Haemonchus contortus larvae on pasture at Vom, Plateau State, Nigeria. Vet. Res. Com. $14,211-216$.

Pandey, V.S., Chaer, A. \& Dakkak, A., 1989. Effect of temperature on development of the free-living stages of Ostertagia circumcincta. Vet. Parasitol. 32, 193-197.

Pandey, V.S., Chaer, A. \& Dakkak, A., 1993. Effect of temperature and relative humidity on survival of eggs and infective larvae of Ostertagia circumcincta. Vet. Parasitol. 49, 219-227.

Perry, B. D. \& Randolph, T. F., 1999. Improving the assessment of the economic impact of parasitic diseases and of their control in production animals. Vet. Parasitol. 84, 145168.

Pinault, J.L., 2012. Global warming and rainfall oscillation in the 5-10 yr band in Western Europe and Eastern North America. Climate Change 114, 621-650.

Rossanigo, C.E. \& Gruner, L., 1995. Moisture and temperature requirements in faeces for the development of free-living stages of gastrointestinal nematodes of sheep, cattle and deer. J. Helminthol. 69, 357-362.

Rees, G., 1950. Observations on the vertical migration of third stage larvae of Haemonchus contortus (Rud) on experimental plots of Lolium perenne S24 in relation to meteorological and micrometeorological factors. J. Parasitol. 40, 127-143.

Rose, J. H., 1963. Observations on the free-living stages of the stomach worm 
500

501

502

503

504

505

506

507

508

509

510

511

512

513

514

515

516

517

518

519

520

521

Haemonchus contortus. Parasitology. 53, 469-481.

Rose, J. H. \& Small, A. J., 1985. The distribution of the infective larvae of sheep gastrointestinal nematodes in soil and on herbage and the vertical migration of Trichostrongylus vitrinus larvae through the soil. J. Helminthol. 59, 127-135.

Rose, H., Rinaldi, L., Bosco, A., Mavrot, F., De Waal, T., Skuce, P., Charlier, J., Torgerson, P.R., Hertzberg, H., Hendrickx, G., Vercruysse, J., Morgan, E.R., 2015a.

Widespread anthelmintic resistance in European farmed ruminants: a systematic review. Vet. Rec. 176, 21, doi:10.1136/vr.102982.

Rose, H., Wang, T., Van Dijk, J., \& Morgan, E.R., 2015b. GLOWORM-FL: A simulation model of the effects of climate and climate change on the free-living stages of gastro-intestinal nematode parasites of ruminants. Ecol. Model. 297, 232-245.

Rose, H., Caminade, C., Bolajoko, M.B., Phelan, P., van Dijk, J., Baylis, M., Williams, D., Morgan, E.R., 2016. Climate-driven changes to the spatio-temporal distribution of the parasitic nematode, Haemonchus contortus, in sheep in Europe, Global Change Biol. $22,1271-1285$.

Rose Vineer, H., Steiner, T., Knapp-Lawitzke, F., Bull, K., von Son-de Fernex, E., Bosco, A., Hertzberg, H., Demeler, J., Rinaldi, L., Morrison, A.A., Skuce, P., Bartley, D.J., Morgan, E.R., 2016. Implications of between-isolate variation for climate change impact modelling of Haemonchus contortus populations. Vet. Parasitol. 229, 144-149.

Sands, B., Wall, R., 2017. Dung beetles reduce livestock gastrointestinal parasite availability on pasture. J. Appl. Ecol. 54, 1180-1189.

Silangwa, S.M. \& Todd, A.C., 1964. Vertical migration of trichostrongylid larvae on 
522

523

524

525

526

527

528

529

530

531

532

533

534

535

536

537

538

539

540

541

542

grasses. J. Parasitol. 50, 278-285.

Silva, B.F. et al., 2008. Vertical migration of Haemonchus contortus third stage larvae on Brachiaria decumbens grass. Vet. Parasitol 158, 85-92.

Skinner, W.D. \& Todd, K.S., 1980. Lateral migration of Haemonchus contortus larvae on pasture. Am. J. Vet. Res. 41, 395-398.

Todd, K.S., Levine, N.D. \& Boatman, P.A., 1976. Effect of temperature on survival of free-living stages of Haemonchus contortus. Am. J. Vet. Res. 37, 991-992.

Troell, K., Waller, P.J \& Hoglund, J., 2005. The development and overwintering survival of free-living larvae of Haemonchus contortus in Sweden. J. Helminthol. 79, 373-379.

Van Bezooijen, J., 2006. Methods and Techniques for Nematology. Wageningen: Wageningen University. p. 19.

Van Dijk, J., De Louw, M., Kalis, L. \& Morgan, E.R., 2009. Ultraviolet light increases mortality of nematode larvae and can explain patterns of larval availability at pasture. Int. J. Parasitol. 39, 1151-1156.

Van Dijk, J., Morgan, E.R., 2010. Variation in the hatching behaviour of Nematodirus battus: Polymorphic bet hedging? Int. J. Parasitol. 40, 675-681.

Van Dijk, J., Sargison, N.D., Kenyon, F., Skuce, P.J., 2010. Climate change and infectious disease: helminthological challenges to farmed ruminants in temperate regions. Animal. 4, 377-392.

Van Dijk, J., Morgan, E.R., 2011. The influence of water on the migration of infective trichostrongyloid larvae onto grass. Parasitology. 138, 1-9. 
Van Wyk, J.A., Mayhew, E., 2013. Morphological identification of parasitic nematode infective larvae of small ruminants and cattle: A practical lab guide. Onderstepoort J. Vet. Res. 80, 1-14.

Veglia, F., 1915. The anatomy and life history of Haemonchus contortus (Rud.), $3^{\text {rd }}$ and $4^{\text {th }}$ Reports of the Director of Veterinary Research, 347-500.

Waghorn, T.S, Leathwick, D.M, Chen, L.Y, Gray, R.A.J, Skipp, R. A, 2002. Influence of nematophagous fungi, earthworms and dung burial on development of the free-living stages of Ostertagia (Teladorsagia) circumcincta in New Zealand. Vet. Parasitol. 201, $119-129$

Waghorn, T.S, Reynecke, D.P, Oliver, A.M, Miller, C.M, Vlassoff, A, Koolaard, J.P, Leathwick, D.M., 2011. Dynamics of the free-living stages of sheep intestinal parasites on pasture in the North Island of New Zealand. 1. Patterns of seasonal development. N. Z. Vet. J. 59, 279-286.

Walker, J.G., Evans, K.E., Rose Vineer, H., Van Wyk, J.A., Morgan, E.R., 2018. Prediction and attenuation of seasonal spillover of parasites between wild and domestic ungulates in an arid mixed-use system. J. Appl. Ecol. 2018;00:1-11. https://doi.org/10.1111/1365-2664.13083

Waller, P.J., 1997. Anthelmintic resistance. Vet. Parasitolo, 72, 391-412.

Wang, T., Van Wyk, J.A., Morrison, A., Morgan, E.R., 2014. Moisture requirements for the migration of Haemonchus contortus third stage larvae out of faeces. Vet. Parasitol. $204,258-264$. 
567 Fig. 1. Regression of hourly migration rate out of sheep faeces against temperature for 568 Haemonchus contortus $\mathrm{L} 3 . \mathrm{R}^{2}=0.292, \mathrm{~F}_{2,21}=4.341, \mathrm{p}=0.026$; regression equation $\mathrm{y}$ $569=-0.0002 \mathrm{~T}^{2}+0.0065 \mathrm{~T}+0.1417$.

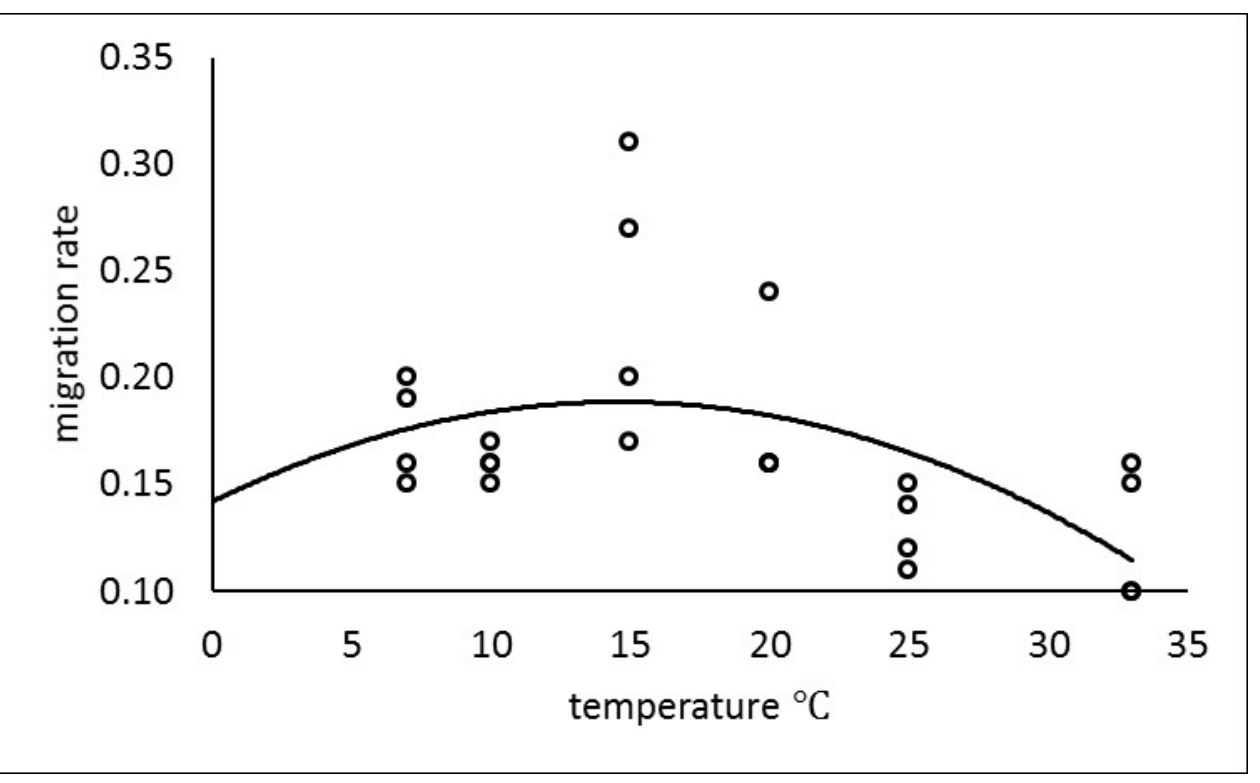

571

572 Fig. 2. Recovery of Haemonchus contortus L3 from grass 6 and 24 hours following

573 wetting of sheep faeces by simulated rainfall, and from the faeces by Baermann 574 extraction after 24 hours. Warm and cooled treatments were applied in glasshouses at 57522.5 and $19.4{ }^{\circ} \mathrm{C}$ respectively. Error bars represent standard error. There was no 576 significant difference in FMC change between the two greenhouses. 


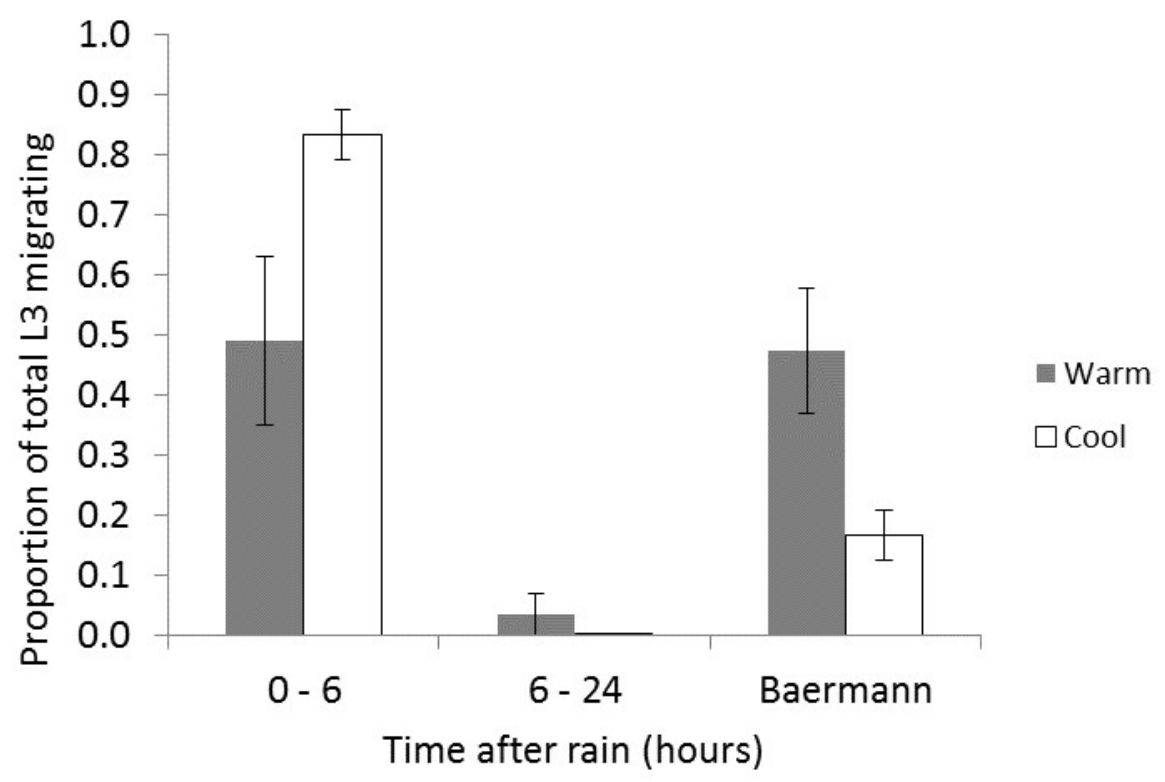

577

578 Fig. 3. Mean faecal moisture content (FMC) change in sheep faecal samples placed on 579 grass turf in warm $\left(22.5^{\circ} \mathrm{C}\right)$ and cooled $\left(19.4{ }^{\circ} \mathrm{C}\right)$ glasshouses. Artificial rainfall was 580 administered once at the starting point ( 9 am). Error bars represent standard error. There 581 was no significant difference in FMC change between the two greenhouses.

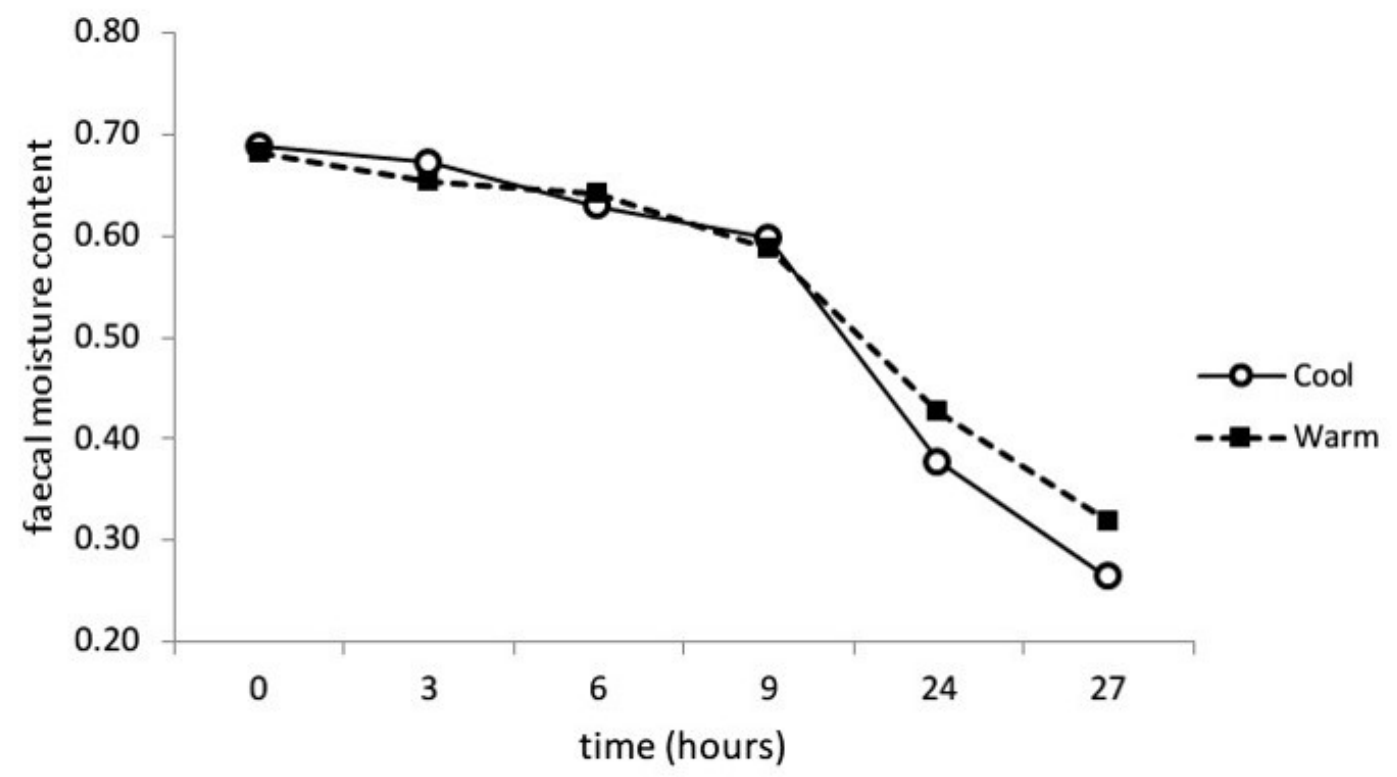

Fig. 4. Proportion of Haemonchus contortus L3 recovered from herbage after different 
588 and cooled $\left(19.4{ }^{\circ} \mathrm{C}\right)$ greenhouses. Error bars indicate standard error.

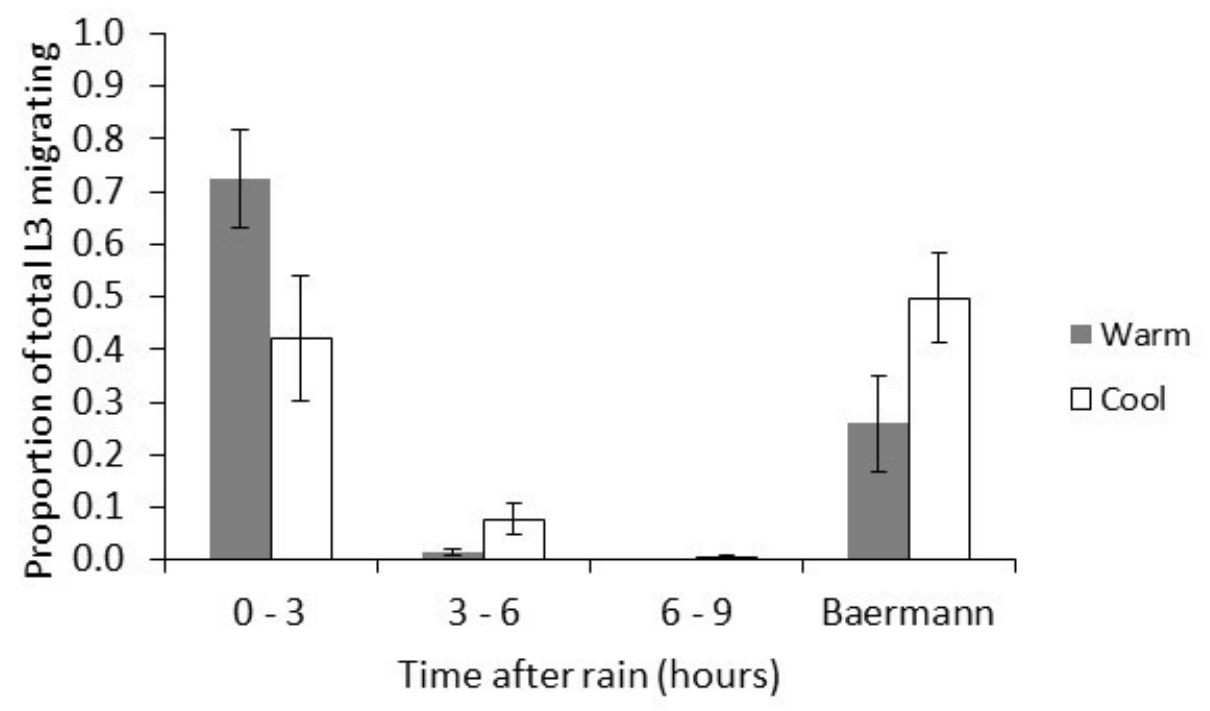

589

590

591 Fig. 5. The number of L3 observed in the first 3 hours after artificial rainfall and the number predicted from the regression of migration rate against temperature (Pearson $r$ $593=0.912, \mathrm{p}=0.002$ ). Data from warm and cooled greenhouses were pooled for analysis.

594 The solid line represents unity (i.e. the line of perfect prediction). 


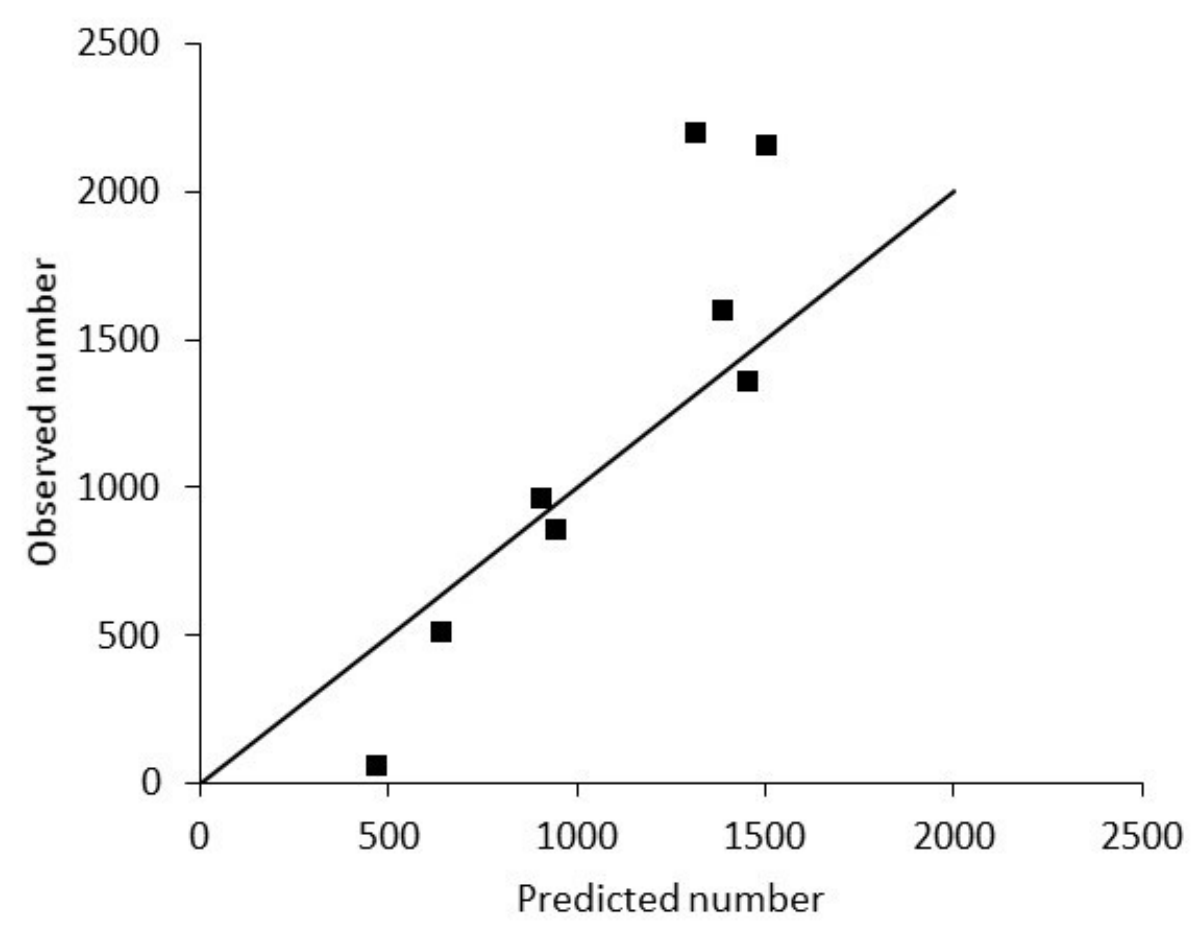

595

596 Fig. 6. Change in faecal moisture content (FMC) of sheep faeces over time, in the field

597 under four different treatments. Error bars represent standard error of four replicates.

598 There was a rain event between 28 and 44 hours; the amount of rain was not measured.

599 Short $/$ long $=$ short and long grass; sun / shade = unshaded or shaded by cardboard

600 canopy. The dotted line represents the approximate lower FMC threshold that stops L3

601 migration from faeces (Wang et al. 2014). 


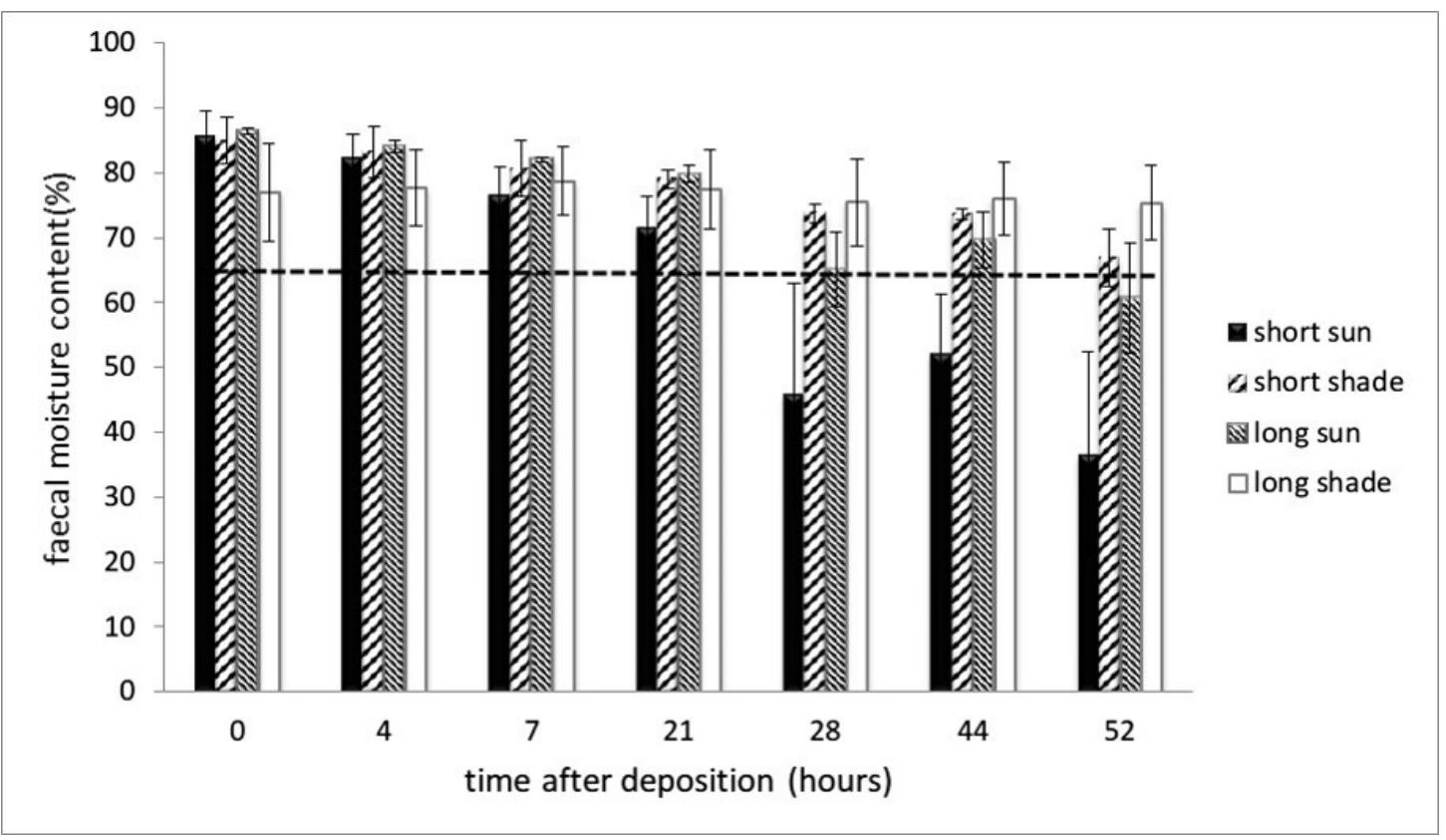

602 